Article

\title{
Significant Improvement in the Scheelite Heating Flotation with Sodium Sulfide
}

\author{
Jianhua Kang ${ }^{1,2}$, Yuanchao Liu ${ }^{1,2}$, Sultan Ahmed Khoso ${ }^{1,2}$, Yuehua Hu ${ }^{1,2, *}$, Wei Sun ${ }^{1,2, *}$ and \\ Runqing Liu ${ }^{1,2}$ (D) \\ 1 School of Minerals Processing and Bioengineering, Central South University, Changsha 410083, China; \\ kangjianhua@csu.edu.cn (J.K.); liuyuanchaocsu@163.com (Y.L.); sultan.khoso@faculty.muet.edu.pk (S.A.K.); \\ liurunqing@126.com (R.L.) \\ 2 Key Laboratory of Hunan Province for Clean and Efficient Utilization of Strategic Calcium-Containing \\ Mineral Resources, Central South University, Changsha 410083, China \\ * Correspondence: hyh@csu.edu.cn (Y.H.); sunmenghu@csu.edu.cn (W.S.); \\ Tel.: +86-0731-88830482 (Y.H. \& W.S.)
}

Received: 22 November 2018; Accepted: 7 December 2018; Published: 12 December 2018

\begin{abstract}
An efficiently optimized reagent regime was investigated to improve scheelite heating flotation. The scheelite grade and recovery in the plant were significantly improved by $5 \%$ and $6 \%$, respectively, which remarkably augmented the economic profit by $\$ 260,000$ per month. The interaction mechanisms of sodium sulfide and sodium oleate with scheelite, calcite and fluorite were evaluated by adsorption amount and Fourier transform infrared (FTIR) analyses. Sodium sulfide exhibited an excellent ability to promote the adsorption and desorption of sodium oleate on the scheelite surface and from the calcite and fluorite surfaces, thus facilitating the separation of scheelite from fluorite and calcite.
\end{abstract}

Keywords: scheelite; Petrov process; sodium sulfide; water glass; combinatory reagent

\section{Introduction}

Tungsten is a strategic metal for stockpiling in many countries because of its significant economic importance and high supply risk [1]. Tungsten has been applied in many industries without other substitutes, especially in the defense and high-technology fields, given its unique properties, such as extreme hardness, wear resistance and high melting point [2]. Approximately $80 \%$ of the global world tungsten concentrate is produced from China, but the demand for tungsten metal from other countries is still not satisfied [3]. Therefore, improving the utilization of tungsten natural resources will be an effective approach to alleviate the growing global demand for tungsten.

Scheelite $\left(\mathrm{CaWO}_{4}\right)$ and wolframite $\left[(\mathrm{Mn}, \mathrm{Fe}) \mathrm{WO}_{4}\right]$ are the primary natural resources of tungsten with economic importance and generally concentrated by flotation, gravity and magnetic separation. Scheelite flotation has become a research hot spot in recent years because of the depletion of wolframite resources. Many methods, especially selective reagents [4], effective equipment [5,6], optimization of flowsheet [7] and recovery of associated scheelite from molybdenum ore [8], have been conducted to improve the utilization of scheelite. Selective collectors, such as hydroxamic acids [9], quaternary ammonium salts [10], dodecylamine [11], amino phosphoric acids [12] and mixed collectors [13,14], have been investigated to improve the flotation of scheelite. Effective depressants, such as water glass (sodium silicate, $\mathrm{Na}_{2} \mathrm{O} \cdot \mathrm{mSiO}_{2} \cdot \mathrm{nH}_{2} \mathrm{O}$ ), acidified sodium silicate $[15,16]$, aluminum-sodium silicate polymer [17], phosphates [18], tannins [19], etidronic acid [20] and calcium lignosulphonate [21], are used to enhance the separation of scheelite from calcium-bearing minerals. 
However, the flotation of scheelite is markedly related to the type of associated gangue minerals. Scheelite associated with oxide-silicate minerals could be efficaciously selected with water glass or phosphates to obtain qualified concentrates at room temperature. However, scheelite associated with calcium-bearing minerals, such as calcite and fluorite, is difficult to separate due to their similar surface properties and floatability. Heat cleaning is widely applied to separate scheelite from calcium-bearing gangue minerals, because of its good adaptability to different ore types, high efficiency and stable operation [22]. The classical Petrov process involves the concentration of rough concentrates and strong agitation at high temperature $\left(85-95^{\circ} \mathrm{C}\right)$ with a large amount of water glass for desorbing the fatty acid collector from gangue minerals surfaces, reagent removal, repulping and flotation [23]. However, when the scheelite ore is associated with high-grade calcium-bearing gangue minerals, the classical Petrov process cease to be effective in achieving the ideal concentrate grade and recovery. Combinatory depressant, such as sodium hydroxide [24], lime [25] or sodium sulfide [26,27] combined with water glass, has been demonstrated to strengthen the selective depression of calcite and fluorite and improve scheelite flotation. These studies have shown that adding the proper amount of sodium hydroxide or sodium sulfide during desorption can effectively reduce the dose of water glass and improve the grade and recovery of the scheelite concentrate.

The tungsten plant in Hunan is one of the largest tungsten concentrate producers in China. Scheelite and wolframite are synchronously enriched through mixed flotation and then separated by a high-gradient magnetic separator. Calcite and fluorite are also accumulated in the rough scheelite concentrate $\left(\mathrm{WO}_{3}, 5-10 \%\right)$, and their grades reach $20 \%$ and $25 \%$, respectively. Scheelite is subjected to the modified Petrov process, in which a collector (GYR), sodium hydroxide, sodium sulfide and water glass are used for heat cleaning to depress calcium-bearing gangue minerals and obtain qualified scheelite concentrate. However, the abundant water glass used in heat cleaning inevitably depresses scheelite to some extent, resulting in the low recovery of the cleaning circuit.

In this study, the effects of sodium hydroxide, sodium sulfide and water glass on scheelite flotation were systematically demonstrated by laboratory-scale experiments. Optimization of the reagent regime significantly improved the grade and recovery of scheelite flotation. The technical and economic feasibility of the application of a new reagent regime was investigated by industrial tests at the plant. The interaction mechanism of sodium sulfide and sodium silicate with scheelite, calcite and fluorite was evaluated by adsorption amount and Fourier transform infrared (FTIR) analyses.

\section{Materials and Methods}

\subsection{Materials}

Rough scheelite concentrate produced from the roughing circuit was taken from a tungsten flotation plant in Hunan, China. The ore was scheelite $\left(\mathrm{WO}_{3}, 5-10 \%\right)$, whilst the main gangue minerals were calcite (15-20\%) and fluorite (20-25\%). The rough scheelite concentrate was further cleaned to obtain the qualified scheelite concentrate by the Petrov process that was widely used to separate scheelite from calcite and fluorite. The fatty acid collector (GYR), sodium hydroxide, sodium sulfide and water glass used in the scheelite heat cleaning were technically pure and taken from the reagent preparation workshop in the plant.

The pure minerals used in the experiment were natural mineral crystals prepared through picking, grinding, and screening. The particle size distribution of the minerals was $0.037-0.074 \mathrm{~mm}$, which was screened with standard screens. The purities of scheelite, calcite and fluorite were $96.34 \%, 95.98 \%$ and $98.84 \%$, respectively, which were determined by chemical analysis. The sodium oleate, sodium silicate ( $m=1 \pm 0.3)$, sodium sulfide and sodium hydroxide used in the adsorption amount and FTIR analyses were analytically pure and purchased from Xilong Chemical Co., Ltd., Guangzhou, China. 


\subsection{Experimental Procedures}

\subsubsection{Scheelite Heating Flotation Experiments}

Laboratory-scale tests were performed with the flotation machine (XFDIV, Jilin Prospecting Machinery Factory, Changchun, China) in the plant. The raw ore undergone comminution, grinding and classification, and the particle size distribution of $-0.074 \mathrm{~mm}$ reached $80-85 \%$. After the recovery of molybdenum and bismuth, the tungsten roughing was conducted to obtain the rough concentrate of scheelite and wolframite. The scheelite and wolframite are separated by a high-gradient magnetic separator. The rough scheelite concentrate was pumped to a thickener for concentration and de-sliming. The rough scheelite concentrate pulp (solid, 55\%) taken from the underflow of the thickener in the plant was adequately homogenized, separated into uniform samples with same weights and prepared for the flotation tests. The samples were placed on the thermostatic magnetic stirrer for even stirring, and then GYR, sodium sulfide and sodium hydroxide were added. When the sample was heated to $95^{\circ} \mathrm{C}$, water glass was added. Then, the mixture was stirred at a constant temperature $\left(90^{\circ} \mathrm{C}\right)$ for $1 \mathrm{~h}$. After the complete reaction, the pulp density was adjusted to $35 \%$ with cold water to prepare for flotation. The detailed flowsheet of scheelite heating flotation is described in Figure 1. The closed-circuit test was performed with the new and old reagent regimes to compare their performance in scheelite heating flotation. The old reagent regime involved GYR $1.5 \mathrm{~kg} / \mathrm{t}$, sodium sulfide $5 \mathrm{~kg} / \mathrm{t}$, sodium hydroxide $2 \mathrm{~kg} / \mathrm{t}$ and water glass $95 \mathrm{~kg} / \mathrm{t}$. The new reagent regime referred to GYR $1.5 \mathrm{~kg} / \mathrm{t}$, sodium sulfide $8 \mathrm{~kg} / \mathrm{t}$, sodium hydroxide $2 \mathrm{~kg} / \mathrm{t}$ and water glass $90 \mathrm{~kg} / \mathrm{t}$. The detailed closed-circuit flowsheet of scheelite heating flotation is presented in Figure 2. The concentrates, middlings and tailings were filtered, dried, weighed and sampled for $\mathrm{WO}_{3}$ analysis.

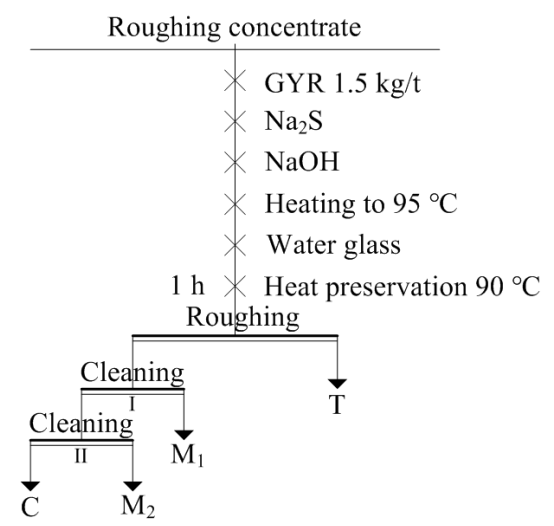

Figure 1. Flowsheet of scheelite heating flotation (concentrates (C), middlings (M) and tailings (T)).

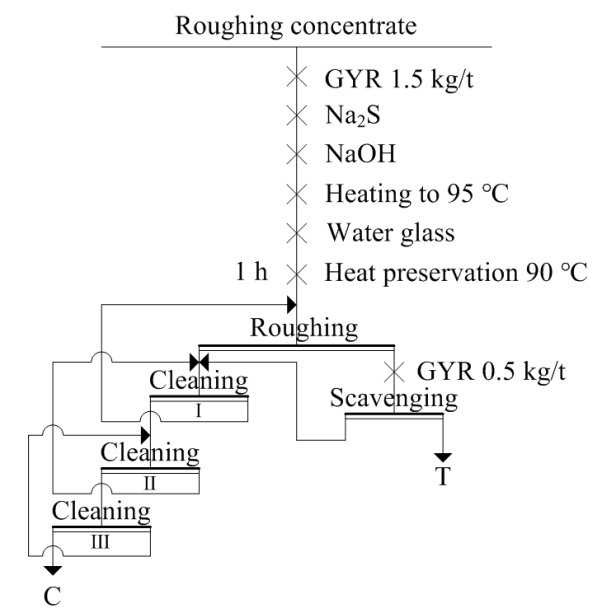

Figure 2. Closed-circuit flowsheet of scheelite heating flotation. 


\subsubsection{Industrial Tests}

Industrial tests were conducted at the heat-cleaning workshop in the plant. The fatty acid collector (GYR) was supplied by Guangdong institute of resources comprehensive utilization. The sodium hydroxide, sodium sulfide and water glass were supplied by Chenzhou Sancheng Chemical Co., Ltd., Chenzhou, China. The reagent regime of the roughing circuit remained unchanged during the industrial tests. The industrial test procedure of scheelite cleaning flotation was similar to that of a laboratory-scale experiment. The rough scheelite concentrate pulp discharged from the thickener was poured into the agitation vat. The GYR, sodium sulfide and sodium hydroxide were added to the pulp in sequence. Then, the mixture was heated by high-temperature steam with strong stirring. When the temperature reached $95^{\circ} \mathrm{C}$, the water glass was added. Then, the mixture was stirred at $90{ }^{\circ} \mathrm{C}$ for $1 \mathrm{~h}$. After the complete reaction, the pulp density was adjusted to $35 \%$ with cold water to prepare for flotation. Compared with those of the old reagent regime (sodium sulfide $5 \mathrm{~kg} / \mathrm{t}$, water glass $95 \mathrm{~kg} / \mathrm{t}$ ), the GYR $(1.5 \mathrm{~kg} / \mathrm{t})$ and sodium hydroxide $(2 \mathrm{~kg} / \mathrm{t})$ doses in the cleaning circuit were kept constant. Moreover, the sodium sulfide dose was increased to $8 \mathrm{~kg} / \mathrm{t}$, and the water glass dose was decreased to $90 \mathrm{~kg} / \mathrm{t}$. During the industrial tests, the samples of feeding rough concentrate, final concentrate and tailing in the scheelite cleaning circuit were continuously taken every $2 \mathrm{~h}$. The mixed samples were filtered, dried and sampled for $\mathrm{WO}_{3}$ analysis. In order to reduce the error, each sample was analyzed three times to obtain the average value as the final result. The new reagent regime was applied on July 2015 , and the details of the scheelite cleaning circuit from June to August were collected to analyze the scheelite flotation and further confirm the feasibility for the technology application and economy of the proposed regime.

\subsubsection{Adsorption Amount Analysis}

The adsorption amount of the collector on the mineral surface is a key factor that influences the mineral flotation. The change in the adsorption amount before and after reacting with reagents could explain the flotation behavior of the minerals [28]. The adsorption amount was determined by the total carbon method that uses a TOC analyzer (TOC-V-CPH, Shimadzu, Kyoto, Japan) to measure the organic carbon content that has a linear relationship with the sodium oleate concentration in the solution. Organic carbon is the difference between the total carbon and inorganic carbon, and this value is used to calculate the residual concentration of sodium oleate after reacting with minerals. The detailed experimental procedures to determine the influence of reagent dose and temperature on the change in the adsorption amount are as follows.

(1) Reagent dose: The minerals $(2 \mathrm{~g})$ mixed with $40 \mathrm{~mL}$ of deionized water were added to the conical flasks placed on a magnetic stirrer $[28,29]$. The $\mathrm{pH}$ of the mixture was adjusted to $13.5 \mathrm{using}$ a pH meter (pHS-3C, Shanghai INESA Scientific Instrument Co., Ltd., Shanghai, China) with NaOH aqueous solution. Sodium oleate $\left(2 \times 10^{-3} \mathrm{~mol} / \mathrm{L}\right)$ was added to the conical flasks. After $3 \mathrm{~min}$, different doses of sodium silicate $\left(0,5,8,12,16,20\right.$ and $\left.24 \times 10^{-3} \mathrm{~mol} / \mathrm{L}\right)$ or sodium sulfide $(0,5,10$, $30,50,70$ and $\left.100 \times 10^{-4} \mathrm{~mol} / \mathrm{L}\right)$ were added to the mixture. The mixture was placed on a water bath thermostat shaker $\left(90^{\circ} \mathrm{C}\right)$ to adequately react for $1 \mathrm{~h}$. Then, the mixture was centrifuged, and the supernatant was collected for TOC analysis.

(2) Temperature: The procedure was similar to that of reagent dose. The mixture was stirred at $90{ }^{\circ} \mathrm{C}$ and $25^{\circ} \mathrm{C}$ for $1 \mathrm{~h}$ at $\mathrm{pH} 13.5$, sodium oleate dose of $2 \times 10^{-3} \mathrm{~mol} / \mathrm{L}$ and sodium silicate dose of $1.2 \times 10^{-2} \mathrm{~mol} / \mathrm{L}$ (or sodium sulfide dose of $5 \times 10^{-3} \mathrm{~mol} / \mathrm{L}$ ). Then, the mixture was centrifuged, and the supernatant was collected for TOC analysis.

The absorption amount $\left(\Gamma, \mathrm{mol} / \mathrm{m}^{2}\right)$ was quantified by Equation (1). The change in the absorption amount $(\eta, \%)$ was calculated by Equation (2). The specific surface areas of scheelite, calcite and fluorite measured by the BET method were $0.906,0.461$ and $0.067 \mathrm{~m}^{2} / \mathrm{g}$, respectively.

$$
\Gamma=\frac{\left(C_{i}-C_{r}\right) \times V}{m \times S_{B E T}}
$$




$$
\eta=\frac{\Gamma_{n}-\Gamma_{o}}{\Gamma_{o}} \times 100 \%
$$

where $C_{i}$ and $C_{r}$ refer to the initial and residual concentrations (mol/L) of sodium oleate; $V$ is the volume of the solution; $m$ is the mineral weight $(\mathrm{g}) ; S_{B E T}$ is the specific surface area $\left(\mathrm{m}^{2} / \mathrm{g}\right)$ of minerals; and $\Gamma_{n}$ and $\Gamma_{o}$ are the absorption amounts at a certain condition and its relative condition, respectively.

\subsubsection{FTIR Analysis}

The mineral suspension was prepared by adding $1.0 \mathrm{~g}$ of minerals $(-2 \mu \mathrm{m})$ to deionized water $[4,30]$, and the $\mathrm{pH}$ was adjusted to 13.5 . Sodium oleate $\left(2 \times 10^{-3} \mathrm{~mol} / \mathrm{L}\right)$ and sodium silicate $\left(1.2 \times 10^{-2} \mathrm{~mol} / \mathrm{L}\right)$ or sodium sulfide $\left(5 \times 10^{-3} \mathrm{~mol} / \mathrm{L}\right)$ were added to the mineral suspension. The mixture was placed on a water bath thermostat shaker $\left(90^{\circ} \mathrm{C}\right)$ to adequately react for $1 \mathrm{~h}$. Then, the mixture was filtered with a microporous membrane. The filtered minerals were washed in triplicate with distilled water and air dried at room temperature for FTIR analysis (Nicolet 6700, Thermo Fisher Scientific, Waltham, MA, USA).

\section{Results and Discussion}

\subsection{Scheelite Heating Flotation Experiments}

\subsubsection{Effect of Desorption Reagent Dose on Scheelite Heating Flotation}

Scheelite has surface properties and floatability similar to those of calcite and fluorite because of the same calcium ion species on their surfaces [31]. Calcium minerals have analogical reactive center and surface reactivity to traditional fatty acid collectors [30]. After primary enrichment by roughing, the classical Petrov process is commonly utilized to further separate scheelite from other calcium minerals [18]. The fatty acid collector is desorbed from the calcite and fluorite surfaces under the effect of water glass at high temperature [7]. In addition, sodium hydroxide and sodium sulfide are jointly applied with water glass to enhance the separation of scheelite from calcium-bearing minerals $[20,26]$. Figure 3 presents the scheelite heating flotation with different desorption reagents. Figure 3a shows that the scheelite grade was significantly improved from $22 \%$ to $50 \%$ as the water glass dose was increased from $80 \mathrm{~kg} / \mathrm{t}$ to $90 \mathrm{~kg} / \mathrm{t}$. The recovery acutely decreased from $80 \%$ to $63 \%$. Figure $3 \mathrm{~b}$ shows that scheelite grade was effectively increased from $15 \%$ to $52 \%$ when sodium hydroxide dose reached $3 \mathrm{~kg} / \mathrm{t}$ compared with that without sodium hydroxide, and the recovery was drastically reduced from $82 \%$ to $57 \%$. These results indicate that water glass combined with sodium hydroxide could markedly depress gangue minerals at high temperature, which could effectually improve the grade of scheelite concentrate. However, scheelite, as a calcium mineral, was also depressed to a certain extent. Figure $3 \mathrm{c}$ shows that scheelite grade was observably improved from $32 \%$ to $68 \%$ as sodium sulfide dose was increased from $0 \mathrm{~kg} / \mathrm{t}$ to $8 \mathrm{~kg} / \mathrm{t}$. The recovery was dramatically improved from $60 \%$ to $76 \%$. The results confirm that the combination of sodium sulfide with water glass and sodium hydroxide could significantly improve scheelite heating flotation by synchronously increasing the grade and recovery. 

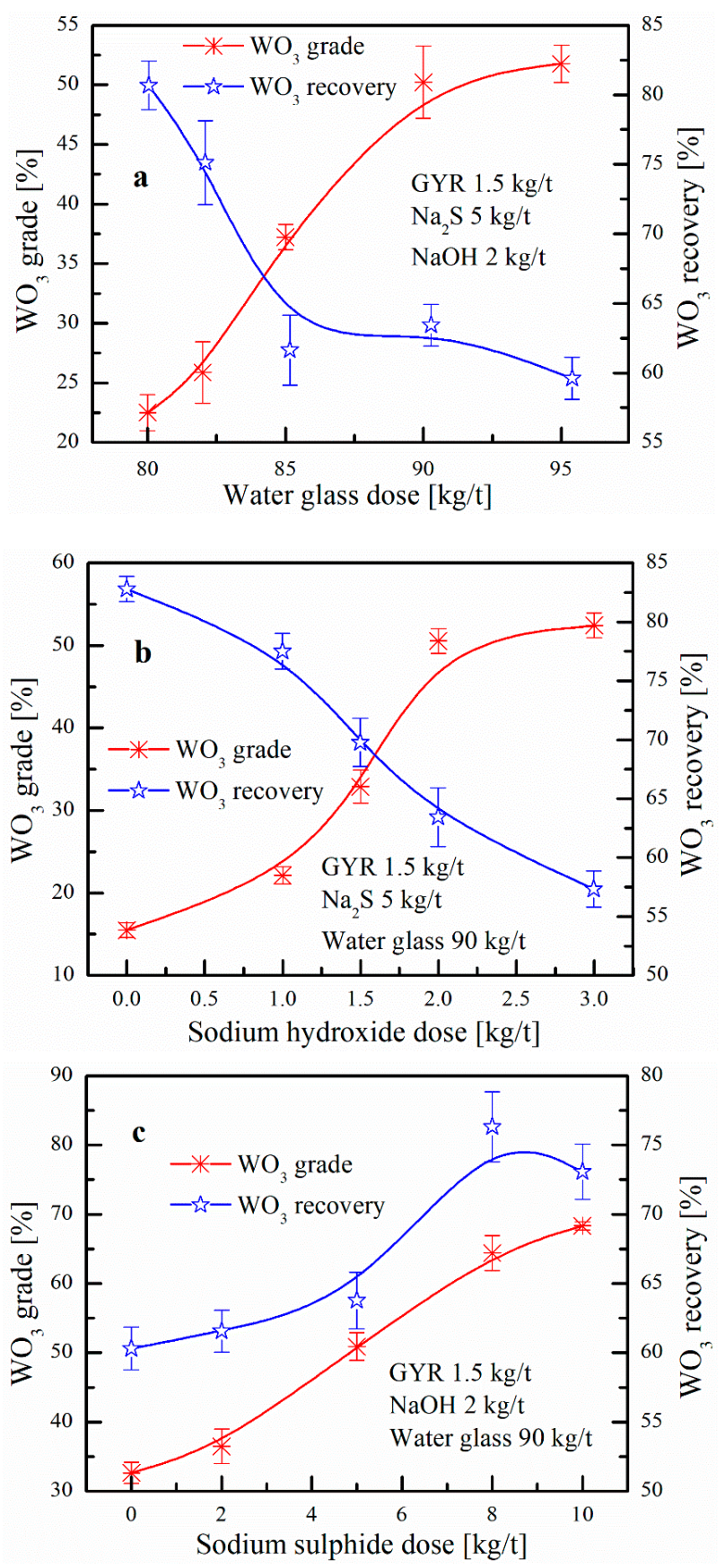

Figure 3. Scheelite heating flotation with water glass (a), sodium hydroxide (b) and sodium sulfide (c).

\subsubsection{Closed-Circuit Experiment Results}

Sodium sulfide exhibits an excellent ability to simultaneously improve the scheelite grade and recovery, whereas water glass depresses scheelite to some extent while depressing other calcium-bearing minerals. Therefore, the new reagent regime augmented the sodium sulfide dose to $8 \mathrm{~kg} / \mathrm{t}$ and reduced the water glass dose to $90 \mathrm{~kg} / \mathrm{t}$. The closed-circuit experiment was conducted using the new and old reagent regimes to demonstrate the effect of sodium sulfide on improving scheelite heating flotation. The results are presented in Figure 4. The scheelite grade and recovery were significantly improved using the new reagent regime compared to using the old reagent regime. The grade was dramatically enhanced from $57.75 \%$ to $66.51 \%$, and the recovery was also remarkably improved from $69.38 \%$ to $83.25 \%$. The results confirm that sodium sulfide played a key role on scheelite heating flotation and could significantly improve the scheelite heating flotation. 


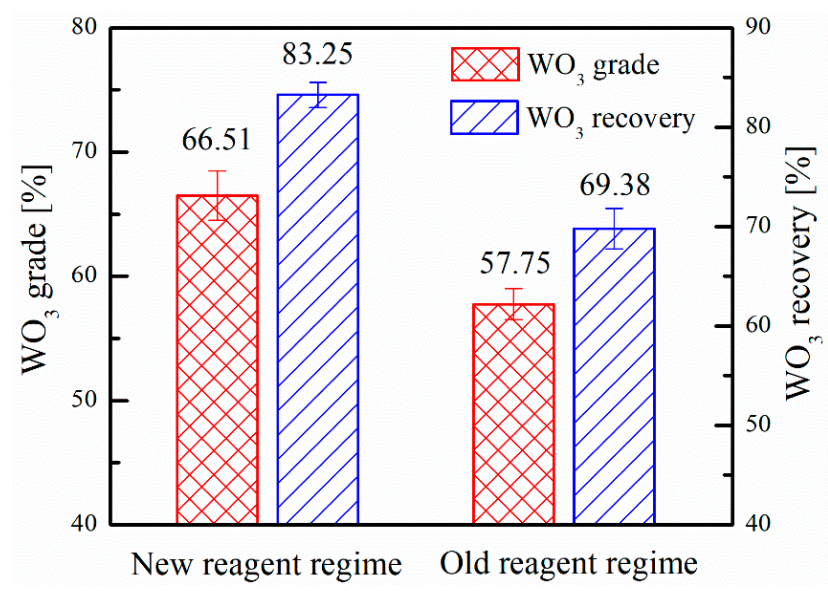

Figure 4. Closed-circuit experiment results of scheelite heating flotation using the new and old reagent regimes.

\subsection{Industrial Tests}

Scheelite processing in the plant mainly includes crushing, grinding and roughing, followed by cleaning with the modified Petrov process to produce scheelite concentrate $\left(\mathrm{WO}_{3}>65 \%\right)$ to meet the requirement of international trading [1]. The cleaning circuit is the most important step of the whole process. The scheelite concentrate grade and recovery directly affect the product quality and output, which are crucial factors that determine the economic benefit of an industry. Although the laboratory-scale experiments reveal excellent results, whether the optimization of the reagent regime could improve scheelite flotation should be further verified through industrial tests. In the early stage of industrial testing, in order to ensure the stability of actual production, the sodium sulfide dose was slowly increased from $5 \mathrm{~kg} / \mathrm{t}$ to $8 \mathrm{~kg} / \mathrm{t}$, and the water glass dose was gently reduced from $95 \mathrm{~kg} / \mathrm{t}$ to $90 \mathrm{~kg} / \mathrm{t}$. In the middle and late stages, the scheelite heating flotation has been significantly improved, and the doses of sodium sulfide and water glass were basically maintained at $8 \mathrm{~kg} / \mathrm{t}$ and $90 \mathrm{~kg} / \mathrm{t}$, respectively. Figure 5 shows the monthly details of scheelite heating flotation with the old and new reagent regimes. In June, the grade of the scheelite concentrate was $61.07 \%$, and the recovery was $86.37 \%$ using the old reagent regime. In July, the sodium sulfide dose was increased from $5 \mathrm{~kg} / \mathrm{t}$ to $8 \mathrm{~kg} / \mathrm{t}$, and the water glass dose was reduced from $95 \mathrm{~kg} / \mathrm{t}$ to $90 \mathrm{~kg} / \mathrm{t}$. The grade of the scheelite concentrate improved to $65.99 \%$, and the recovery reached $92.28 \%$. In August, the doses of sodium sulfide and water glass were consistent with the new reagent regime, and the grade and recovery further improved. The grade of scheelite concentrate reached $66.45 \%$, and the recovery attained $92.84 \%$. Compared with those in June using the old reagent regime, the product grades and recoveries in July and August using the new reagent regime were significantly improved by $5 \%$ and $6 \%$, respectively. These results would produce a remarkable economic benefit. The industrial test results verify that the optimization of the reagent regime effectively improved the scheelite heating flotation.

Compared with the old reagent regime, the change in the cost of scheelite heating flotation using the new reagent regime is mainly due to sodium sulfide and water glass. The results of the economic evaluation of scheelite heating flotation using the old and new reagent regimes are presented in Table 1. In June, the consumption of sodium sulfide and water glass were $19 \mathrm{t}$ and $370 \mathrm{t}$, with corresponding costs of $\$ 6650$ and $\$ 44,400$. The product output was $181 \mathrm{t}$, and the profit was $\$ 3,620,000$. In July, the consumption of sodium sulfide increased to $30 \mathrm{t}$, and the cost was $\$ 10,500$. The consumption of water glass decreased to $350 \mathrm{t}$, and the cost was $\$ 42,000$. However, the product output significantly increased to $194 \mathrm{t}$, and the profit reached $\$ 3,880,000$. In August, the reagent cost and product profit were similar to those in July. Compared with the old reagent regime, the new reagent regime increased the cost of sodium sulfide by approximately $\$ 4000$, reduced the cost of water glass by approximately $\$ 2700$ and improved the product profit by $\$ 270,000$ per month. These results indicate that optimizing the reagent regime could dramatically obtain an extra economic profit of approximately $\$ 260,000$ per month. 
The results of industrial testing and economic evaluation confirm that sodium sulfide significantly improved the product grade and recovery and created a remarkable economic profit. Given the low recovery of the heat cleaning circuit, part of scheelite was not recycled but discharged to the tailings dam, resulting in serious resources waste. The innovation of the reagent regime significantly improved the recovery of the scheelite cleaning circuit, which would effectively enhance the utilization of scheelite and promote the sustainable development of natural mineral resources.

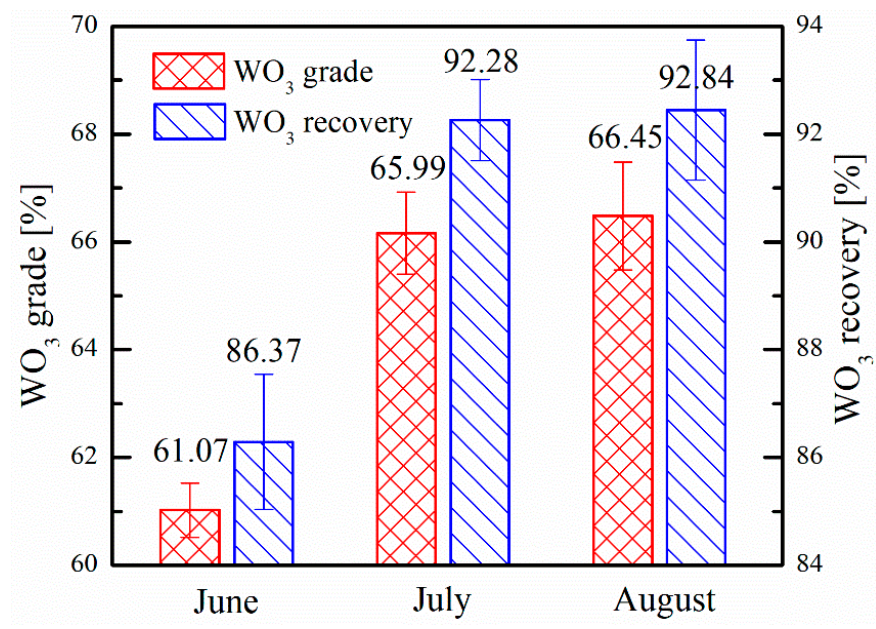

Figure 5. Monthly details of scheelite heating flotation using the old (June) and new (July and August) reagent regimes.

Table 1. Economic evaluation results of scheelite heating flotation using the old (June) and new (July and August) reagent regimes.

\begin{tabular}{ccccccccc}
\hline \multirow{2}{*}{ Items } & \multirow{2}{*}{ Price [\$/t] } & \multicolumn{2}{c}{ June } & \multicolumn{2}{c}{ July } & \multicolumn{2}{c}{ August } \\
\cline { 4 - 9 } & & & Mass [t] & Total [\$] & Mass [t] & Total [\$] & Mass [t] & Total [\$] \\
\hline \multirow{2}{*}{ Product profit } & $\mathrm{WO}_{3}$ & 20,000 & 181 & $3,620,000$ & 194 & $3,880,000$ & 195 & $3,900,000$ \\
\hline \multirow{2}{*}{ Reagent cost } & $\mathrm{Na}_{2} \mathrm{~S}$ & 350 & 19 & 6650 & 30 & 10,500 & 32 & 11,200 \\
& Water glass & 120 & 370 & 44,400 & 350 & 42,000 & 345 & 41,400 \\
\hline \multicolumn{2}{c}{ Profit [\$] } & & \multicolumn{2}{c}{$3,568,950$} & $3,827,500$ & $3,847,400$ \\
\hline
\end{tabular}

\subsection{Adsorption Amount Analysis}

\subsubsection{Effect of Desorption Reagents Dose on the Change in the Adsorption Amount}

The change in the adsorption amount is applied to quantitatively analyze the adsorption and desorption of fatty acid collector on the mineral surface before and after reacting with reagents. Thus, the flotation behavior of the minerals was characterized. In the Petrov process, the fatty acid collector adsorbed on the surfaces of calcite and fluorite will be desorbed under the action of water glass at high temperature with intense stirring, whilst the scheelite is less affected and maintains good floatability to realize the separation from calcite and fluorite [20]. The change in the adsorption amount of sodium oleate on scheelite, calcite and fluoride surfaces before and after the reaction with different doses of sodium silicate or sodium sulfide are presented in Figure 6. Compared with those without sodium silicate, the adsorption amounts of sodium oleate on scheelite, calcite and fluoride surfaces decreased by approximately $3 \%, 20 \%$ and $45 \%$, respectively, with different doses of sodium silicate. These results indicate that the sodium oleate absorbed on the fluorite and calcite surfaces was partly desorbed, whiles the sodium oleate absorbed on the scheelite surface was scarcely desorbed. The changes in the adsorption amount confirm that fluorite and calcite would be seriously depressed by sodium silicate and scheelite would be slightly affected. Compared with those without sodium sulfide, the adsorption amounts of sodium oleate on the calcite and fluoride surfaces decreased by $4 \%$ and $34 \%$, respectively, 
with $5 \times 10^{-3} \mathrm{~mol} / \mathrm{L}$ sodium sulfide. The adsorption amount of sodium oleate on the scheelite surface was increased by $8 \%$. These results indicate that the sodium oleate absorbed on the fluorite surface was partially desorbed, the sodium oleate absorbed on the calcite surface was less desorbed, and sodium oleate absorbed on the scheelite surface was promoted. The changes in the adsorption amount confirm that fluorite would be seriously depressed, calcite would be mildly depressed and scheelite would be activated by sodium sulfide. These phenomena may be the primary reasons for the improvement of scheelite flotation grade and recovery.
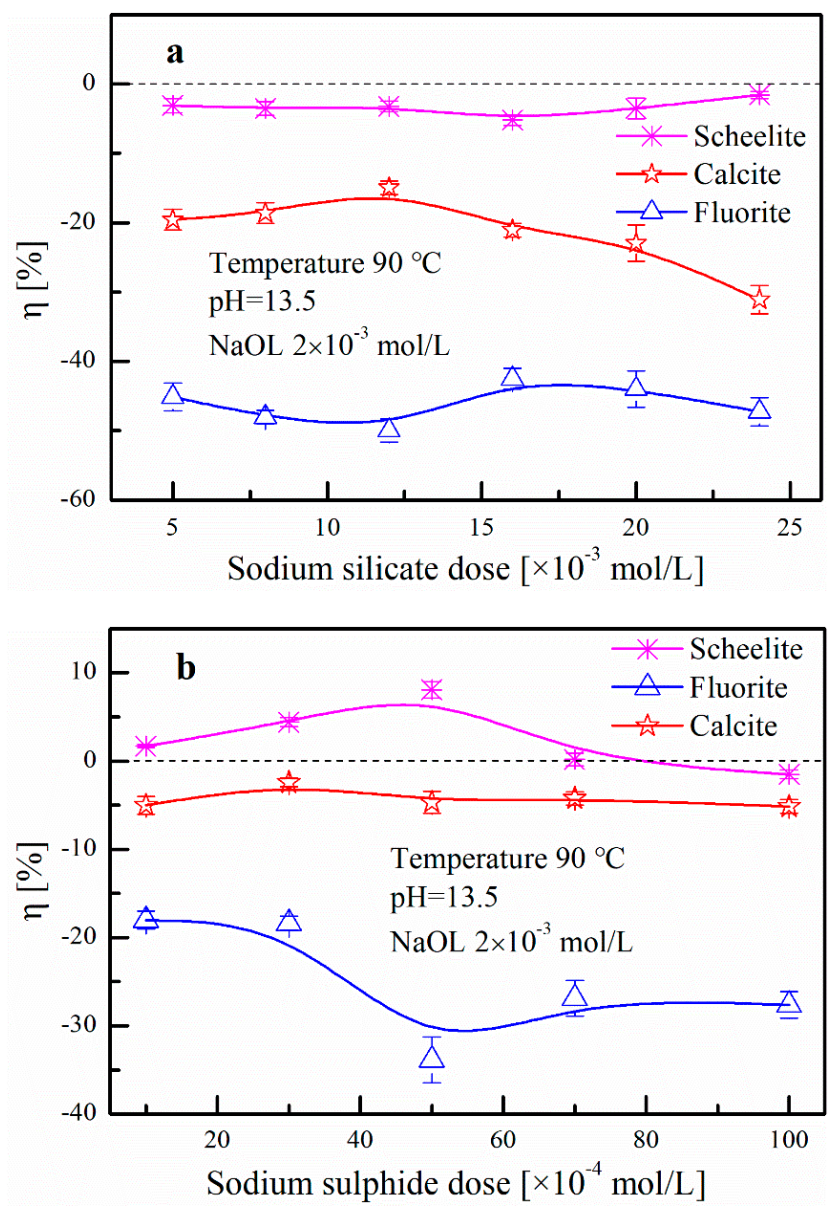

Figure 6. Changes in the adsorption amount of $\mathrm{NaOL}$ on the minerals surfaces at different $\mathrm{Na}_{2} \mathrm{SiO}_{4}(\mathbf{a})$ and $\mathrm{Na}_{2} \mathrm{~S}(\mathbf{b})$ doses compared with those without $\mathrm{Na}_{2} \mathrm{SiO}_{4}$ or $\mathrm{Na}_{2} \mathrm{~S}$.

\subsubsection{Effect of Temperature on the Change in the Adsorption Amount}

The effect of temperature on the adsorption and desorption of sodium oleate on or from the scheelite, calcite and fluorite surfaces was demonstrated by measuring the adsorption amount with sodium silicate or sodium sulfide at $90{ }^{\circ} \mathrm{C}$ and $25{ }^{\circ} \mathrm{C}$. The changes in the adsorption amount of sodium oleate on scheelite, calcite and fluorite surfaces with sodium silicate or sodium sulfide at $90^{\circ} \mathrm{C}$ compared with those at $25{ }^{\circ} \mathrm{C}$ are presented in Figure 7. Compared with those at $25^{\circ} \mathrm{C}$, the adsorption amounts of sodium oleate on scheelite, calcite and fluorite surfaces decreased by $4.57 \%, 6.29 \%$ and $48.84 \%$, respectively, with $1.2 \times 10^{-2} \mathrm{~mol} / \mathrm{L}$ sodium silicate at $90^{\circ} \mathrm{C}$. These results indicate that the sodium oleate absorbed on the fluorite surface was seriously desorbed, and the sodium oleate absorbed on the scheelite and calcite surfaces was scarcely desorbed. The changes in the adsorption amount confirm that fluorite would be severely depressed at high temperature, and scheelite and calcite would be depressed to some extent. Figure $7 \mathrm{~b}$ shows that the adsorption amounts of sodium oleate on the calcite and fluorite surfaces decreased by $5.68 \%$ and $42.38 \%$, respectively, with $5 \times 10^{-3} \mathrm{~mol} / \mathrm{L}$ sodium sulfide at $90{ }^{\circ} \mathrm{C}$ compared with those at $25^{\circ} \mathrm{C}$. By contrast, the adsorption amount of sodium oleate 
on the scheelite surface increased by $24.34 \%$. These results indicate that sodium oleate absorbed on the fluorite surface was desorbed by $42.38 \%$, and the sodium oleate absorbed on scheelite surface was promoted by $24.34 \%$. The changes in the adsorption amount confirm that high temperature was conducive to the adsorption of sodium oleate on the scheelite surface and the desorption of sodium oleate from the fluorite and calcite surfaces. These characteristics would promote the separation of scheelite from fluorite and calcite.
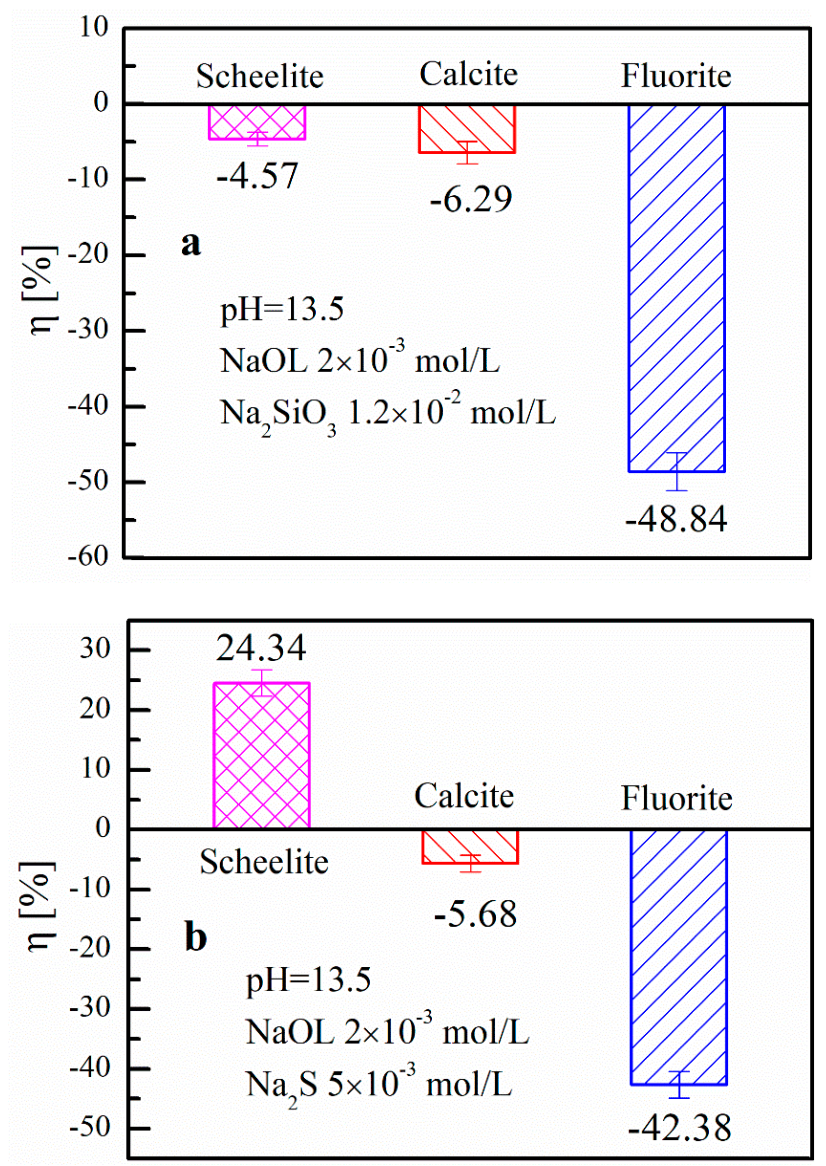

Figure 7. Changes in the adsorption amount of $\mathrm{NaOL}$ on the mineral surfaces with $\mathrm{Na}_{2} \mathrm{SiO}_{4}(\mathbf{a})$ and $\mathrm{Na}_{2} \mathrm{~S}(\mathbf{b})$ at $90{ }^{\circ} \mathrm{C}$ compared with those at $25^{\circ} \mathrm{C}$.

\subsection{FTIR Analysis}

FTIR analysis was conducted to determine the interaction mechanism of minerals with reagents by comparing the changes in the FTIR spectra before and after the reaction of scheelite, calcite and fluorite with sodium oleate, sodium silicate or sodium sulfide. Figure 8 describes the FTIR spectra of scheelite, calcite and fluorite after reacting with sodium oleate, sodium silicate and sodium sulfide. Figure 8 a shows that, after reacting with sodium oleate, the characteristic peaks of sodium oleate [4] at 2920, 2850, 1539 and $1464 \mathrm{~cm}^{-1}$ appeared on the scheelite spectra. The locations of peaks did not significantly shift, and no characteristic peaks of sodium silicate and sodium sulfide were observed on the scheelite spectra after reacting with sodium silicate or sodium sulfide. The intensities of peaks at 2920 and $2850 \mathrm{~cm}^{-1}$ were strengthened after reacting with sodium sulfide, which indicates the increased adsorbed sodium oleate on the scheelite surface. These results indicate that sodium oleate was strongly adsorbed on the scheelite surface through chemical adsorption [32]. Sodium silicate and sodium sulfide were adsorbed on the scheelite surface through electrostatic force [30]. Moreover, sodium sulfide contributed to the adsorption of sodium oleate on the scheelite surface. Figure $8 \mathrm{~b}$ shows the characteristic peaks of sodium oleate at $2923 \mathrm{~cm}^{-1}$ and $2854 \mathrm{~cm}^{-1}$ on the calcite spectra, and the characteristic peaks of sodium silicate and sodium sulfide were absent. The peaks at $2923 \mathrm{~cm}^{-1}$ 
and $2854 \mathrm{~cm}^{-1}$ remained unchanged after reacting with sodium silicate or sodium sulfide, but their intensities significantly weakened because of the desorption of sodium oleate from the calcite surface. Figure $8 \mathrm{c}$ shows similar results, that is, the locations of characteristic peaks did not shift after reacting with sodium silicate or sodium sulfide. The attenuations of the intensities of the sodium oleate characteristic peaks at $2924 \mathrm{~cm}^{-1}$ and $2854 \mathrm{~cm}^{-1}$ indicate the desorption of sodium oleate from the fluorite surface.
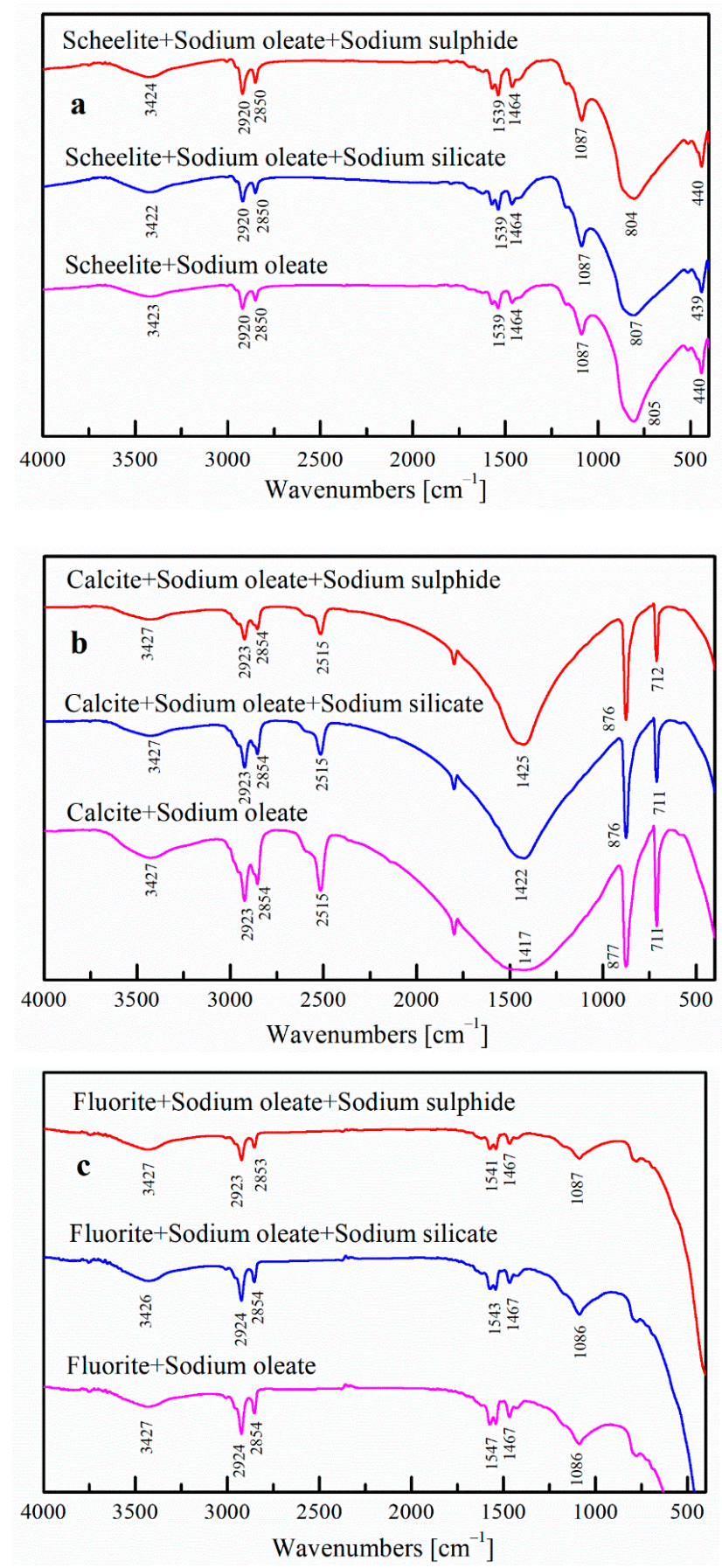

Figure 8. FTIR spectra of scheelite (a), calcite (b) and fluorite (c) after reaction with sodium oleate, sodium silicate or sodium sulfide.

FTIR analysis results confirm that sodium oleate interacted with scheelite, calcite and fluoride through chemical adsorption, whereas sodium silicate and sodium sulfide interacted with these minerals via physical adsorption. Sodium sulfide was beneficial to the adsorption of sodium oleate 
on the scheelite surface. By contrast, sodium sulfide and sodium silicate facilitated the desorption of sodium oleate from the calcite and fluorite surfaces. These results are consistent with those of the adsorption amount analysis and indirectly elucidated the flotation behavior of scheelite under the action of sodium oleate, sodium silicate and sodium sulfide.

\section{Conclusions}

This study introduced an excellent optimization of the reagent regime to improve scheelite heating flotation. Systematic laboratory-scale experiments were conducted to investigate the effects of sodium sulfide and water glass on the scheelite heating flotation. The mechanisms underlying the interaction of sodium sulfide and sodium oleate with scheelite, calcite and fluorite were investigated through the adsorption amount and FTIR analyses. The technical application and economic feasibility of the new reagent regime was confirmed by industrial tests at the plant. The following conclusions were drawn:

(1) Sodium sulfide could effectively improve scheelite heating flotation. The grade and recovery were improved by $9 \%$ and $14 \%$, respectively, using the new reagent regime compared with those with the old reagent regime in the closed-circuit experiment.

(2) Sodium sulfide could promote the adsorption and the desorption of sodium oleate on the scheelite surface and from the calcite and fluorite surfaces, respectively, at high temperature. Sodium silicate could significantly desorb sodium oleate from the calcite and fluorite surfaces. The changes in the adsorption amount would promote the separation of scheelite from fluorite and calcite.

(3) The grade and recovery of scheelite heating flotation were significantly improved by $5 \%$ and $6 \%$, respectively. An additional economic profit of $\$ 260,000$ per month was obtained in the industrial tests at the plant. The innovation of the reagent regime significantly improved the utilization of scheelite and effectively promoted the sustainable development of the natural mineral resources.

Author Contributions: Y.H., W.S. and R.L. conceived and designed the experiments; J.K., Y.L. and S.A.K. performed the experiments and analyzed the date; J.K. wrote the paper.

Acknowledgments: The research was supported by the Natural Science Foundation of China (No. 51374247 and 51634009), Innovation Driven Plan of Central South University (No. 2015CX005), Key Laboratory of Hunan Province for Clean and Efficient Utilization of Strategic Calcium-containing Mineral Resources (No. 2018TP1002), the National 111 Project (No. B14034), the Fundamental Research Funds for the Central Universities of Central South University (No. 150110005), and Collaborative Innovation Center for Clean and Efficient Utilization of Strategic Metal Mineral Resources.

Conflicts of Interest: The authors declare no conflict of interest.

\section{References}

1. Rao, N.K. Beneficiation of tungsten ores in India: A review. Bull. Mater. Sci. 1996, 19, 201-265.

2. Kupka, N.; Rudolph, M. Froth flotation of scheelite-A review. Int. J. Min. Sci. Technol. 2018, 28, 373-384. [CrossRef]

3. Yang, X. Beneficiation studies of tungsten ores-A review. Miner. Eng. 2018, 125, 111-119. [CrossRef]

4. Gao, Y.; Gao, Z.; Sun, W.; Yin, Z.; Wang, J.; Hu, Y. Adsorption of a novel reagent scheme on scheelite and calcite causing an effective flotation separation. J. Colloid Interface Sci. 2018, 512, 39-46. [CrossRef] [PubMed]

5. Zhou, W.; Chen, H.; Ou, L.; Shi, Q. Aggregation of ultra-fine scheelite particles induced by hydrodynamic cavitation. Int. J. Miner. Process. 2016, 157, 236-240. [CrossRef]

6. Li, C.; Gao, Z. Effect of grinding media on the surface property and flotation behavior of scheelite particles. Powder Technol. 2017, 322, 386-392. [CrossRef]

7. Han, H.; Hu, Y.; Sun, W.; Li, X.; Cao, C.; Liu, R.; Yue, T.; Meng, X.; Guo, Y.; Wang, J.; et al. Fatty acid flotation versus bha flotation of tungsten minerals and their performance in flotation practice. Int. J. Miner. Process. 2017, 159, 22-29. [CrossRef]

8. Kang, J.; Chen, C.; Sun, W.; Tang, H.; Yin, Z.; Liu, R.; Hu, Y.; Nguyen, A.V. A significant improvement of scheelite recovery using recycled flotation wastewater treated by hydrometallurgical waste acid. J. Clean. Prod. 2017, 151, 419-426. [CrossRef] 
9. Gao, Y.; Gao, Z.; Sun, W.; Hu, Y. Selective flotation of scheelite from calcite: A novel reagent scheme. Int. J. Miner. Process. 2016, 154, 10-15. [CrossRef]

10. Yang, F.; Sun, W.; Hu, Y.; Long, S. Cationic flotation of scheelite from calcite using quaternary ammonium salts as collector: Adsorption behavior and mechanism. Miner. Eng. 2015, 81, 18-28. [CrossRef]

11. Gao, Z.; Sun, W.; Hu, Y. New insights into the dodecylamine adsorption on scheelite and calcite: An adsorption model. Miner. Eng. 2015, 79, 54-61. [CrossRef]

12. $\mathrm{Hu}, \mathrm{Y} . ; \mathrm{Xu}, \mathrm{Z}$. Interactions of amphoteric amino phosphoric acids with calcium-containing minerals and selective flotation. Int. J. Miner. Process. 2003, 72, 87-94. [CrossRef]

13. Wang, J.; Gao, Z.; Gao, Y.; Hu, Y.; Sun, W. Flotation separation of scheelite from calcite using mixed cationic/anionic collectors. Miner. Eng. 2016, 98, 261-263. [CrossRef]

14. Yan, W.; Liu, C.; Ai, G.; Feng, Q.; Zhang, W. Flotation separation of scheelite from calcite using mixed collectors. Int. J. Miner. Process. 2017, 169, 106-110. [CrossRef]

15. Dong, L.; Jiao, F.; Qin, W.; Zhu, H.; Jia, W. Effect of acidified water glass on the flotation separation of scheelite from calcite using mixed cationic/anionic collectors. Appl. Surf. Sci. 2018, 444, 747-756. [CrossRef]

16. Feng, B.; Luo, X.; Wang, J.; Wang, P. The flotation separation of scheelite from calcite using acidified sodium silicate as depressant. Miner. Eng. 2015, 80, 45-49.

17. Wei, Z.; Hu, Y.; Han, H.; Sun, W.; Wang, R.; Wang, J. Selective flotation of scheelite from calcite using $\mathrm{Al}-\mathrm{Na}_{2} \mathrm{SiO}_{3}$ polymer as depressant and Pb-BHA complexes as collector. Miner. Eng. 2018, 120, $29-34$. [CrossRef]

18. Li, Y.; Li, C. Selective flotation of scheelite from calcium minerals with sodium oleate as a collector and phosphates as modifiers. I. Selective flotation of scheelite. Int. J. Miner. Process. 1983, 10, 205-218.

19. Sarquís, P.E.; Menéndez-Aguado, J.M.; Mahamud, M.M.; Dzioba, R. Tannins: The organic depressants alternative in selective flotation of sulfides. J. Clean. Prod. 2014, 84, 723-726. [CrossRef]

20. Kang, J.; Hu, Y.; Sun, W.; Liu, R.; Yin, Z.; Tang, H.; Meng, X.; Zhang, Q.; Liu, H. A significant improvement of scheelite flotation efficiency with etidronic acid. J. Clean. Prod. 2018, 180, 858-865. [CrossRef]

21. Chen, W.; Feng, Q.; Zhang, G.; Liu, D.; Li, L. Selective flotation of scheelite from calcite using calcium lignosulphonate as depressant. Miner. Eng. 2018, 119, 73-75. [CrossRef]

22. Shepeta, E.D.; Samatova, L.A.; Kondrat'ev, S.A. Kinetics of calcium minerals flotation from scheelite carbonate ores. J. Min. Sci. 2012, 48, 746-753. [CrossRef]

23. Samatova, L.A.; Shepeta, E.D.; Gvozdev, V.I. Poor scheelite ores from primorye deposits mineralogy and processing characteristics and dressing flowsheets. J. Min. Sci. 2012, 48, 565-573. [CrossRef]

24. Lin, R.; Zhang, F.; Zeng, Q.; Chen, Z.; Zhang, X. Experimental research on beneficiation of a Yunnan scheelite mine. Met. Mine 2011, 3, 74-77.

25. Xin, Y.; Jian, J.; Kong, L. Study on dereagent from high temperature thickened slurry in cleaning flotation of scheelite. Min. Mach. 2011, 2, 105-109.

26. Chen, W. Research on application of sodium sulfide in heating concentration of wolframite and scheelite. China Tungsten Ind. 2002, 17, 26-28.

27. Yu, Y.; Sun, C.; Wang, Z.; Shang, Y. The influence of different gangue mineral types on scheelite cleaning separation. Non-Ferr. Met. (Miner. Process. Part) 2016, 1, 47-51.

28. Tian, J.; Xu, L.; Deng, W.; Jiang, H.; Gao, Z.; Hu, Y. Adsorption mechanism of new mixed anionic/cationic collectors in a spodumene-feldspar flotation system. Chem. Eng. Sci. 2017, 164, 99-107. [CrossRef]

29. Lyu, F.; Gao, J.; Sun, N.; Liu, R.; Sun, X.; Cao, X.; Wang, L.; Sun, W. Utilization of propyl gallate as a novel selective collector for diaspore flotation. Miner. Eng. 2019, 131, 66-72. [CrossRef]

30. Deng, L.; Zhao, G.; Zhong, H.; Wang, S.; Liu, G. Investigation on the selectivity of N-((hydroxyamino)-alkyl) alkylamide surfactants for scheelite/calcite flotation separation. J. Ind. Eng. Chem. 2016, 33, 131-141. [CrossRef]

31. Chen, W.; Feng, Q.; Zhang, G.; Yang, Q.; Zhang, C. The effect of sodium alginate on the flotation separation of scheelite from calcite and fluorite. Miner. Eng. 2017, 113, 1-7. [CrossRef]

32. Kang, J.; Fan, R.; Hu, Y.; Sun, W.; Liu, R.; Zhang, Q.; Liu, H.; Meng, X. Silicate removal from recycled wastewater for the improvement of scheelite flotation performance. J. Clean. Prod. 2018, 195, 280-288. [CrossRef]

(C) 2018 by the authors. Licensee MDPI, Basel, Switzerland. This article is an open access article distributed under the terms and conditions of the Creative Commons Attribution (CC BY) license (http://creativecommons.org/licenses/by/4.0/). 